DOI https://doi.org/10.36059/978-966-397-105-6/63-83

\title{
SOLID BIO-FUEL
}

\section{Domnich V. I.}

\section{The general characteristic of the granulation process and the bio-fuel potential of Ukraine}

Granulation is a collection of physical and physicochemical processes that ensure the formation of particles of a certain range of sizes, shapes, required structure and physical properties.

A pellet is a cylinder of milled, pressed wood or other bioraw material. It is 10 to 30 millimeters in length and 6 to 10 millimeters in diameter.

Granulation is carried out in order to improve the quality of both intermediate and finished products. Quality indicators depend on the specifics of the product and its purpose. In the general case, granulation can significantly reduce the tendency of the product to caking, and therefore simplify storage, transportation and dosing; to increase flowability while eliminating dustiness, and thus to improve working conditions in various fields of production. Consider the use of fuel pellets in more detail, as the use of pellets in this area is the most rational and widespread.

Fuel pellets are the environmentally friendly fuel with an ash content of not more than $3 \%$. Burning pellets releases as much $\mathrm{CO}_{2}$ into the atmosphere as was absorbed by the plant during growth. The pellets have a low moisture $(8 \ldots 12 \%)$ and a high density. These qualities provide a high calorific value - while burning of a ton of pellets about 5 thousand $\mathrm{kWh}$ of heat is emitted, which is one and a half times more than while burnin of ordinary firewood. Low moisture is not only an advantage of pellets as a fuel, but also a problem of their production. Agricultural biomass used as fuel has a number of features that distinguish it from traditional energy resources used as an energy source. Some of the characteristics of solid biofuels, primarily external ones (density, particle size, surface specificity), can be modified by grinding and consolidating. At the same time, its main fuel and technological characteristics are considered as of steel.

Below there is the average calorific value of agricultural energy raw materials (previously referred to as agricultural waste) with an absolute moisture of $20 \%$. 


\section{Calorific value of energy raw materials}

Name of energy raw materials

Grain straw

Corn stalks

Branches of fruit trees

Buckwheat husk

Sunflower husk
Calorific value, $\mathrm{MJ} / \mathrm{kg}$

10,5

12,5

10,5

12,5

14,2

For many regions of Ukraine, using solid biofuels is more appropriate than using coal or petroleum products, since biofuels produced from local raw materials are 2 to 4 times cheaper and do not require significant transportation costs for its delivery. They use solid biofuels in the form of straw briquettes, pellets, logs and agricultural waste. Properties of various organic fuels are given in Table 1.

Table 1

Comparative characteristics of properties of different fuels

\begin{tabular}{|l|c|c|c|c|}
\hline \multicolumn{1}{|c|}{ Fuel type } & $\begin{array}{c}\text { Material } \\
\text { moisture, \% }\end{array}$ & $\begin{array}{c}\text { Calorific } \\
\text { value, MJ/kg }\end{array}$ & $\begin{array}{c}\text { Sulphur } \\
\text { content }\end{array}$ & $\begin{array}{c}\text { Ash } \\
\text { content, } \%\end{array}$ \\
\hline Natural Gas & - & $35 \ldots 38$ & 0 & 0 \\
Coal & - & $15 \ldots .25$ & $1 \ldots 3$ & $10 \ldots 35$ \\
Motor fuel & - & 42,5 & 0,2 & 1,0 \\
Masut & - & 42 & 1,2 & 1,5 \\
$\begin{array}{l}\text { Wood chips, } \\
\text { sawdust }\end{array}$ & $40 \ldots 45$ & $10.5 \ldots 12.0$ & 0 & 2,0 \\
$\begin{array}{l}\text { Briquettes, } \\
\text { pellets of wood }\end{array}$ & $7 \ldots 8$ & $16.8 \ldots 21.0$ & 0,1 & 1,0 \\
$\begin{array}{l}\text { Briquettes, } \\
\text { pellets of straw }\end{array}$ & $8 \ldots 10$ & $16,5 \ldots 18,8$ & 0,2 & 3,0 \\
\hline
\end{tabular}

Granulated solid biofuels for boilers consisting of waste wood (bark remains, sawdust, logs, pieces of wood, etc.) must have a calorific value of dry weight higher than $5400 \mathrm{kWh} / \mathrm{t}$; moisture less than 40\%; an average particle size of $50 \times 50 \times 20 \mathrm{~mm}$, with containing of particles of up to $150 \times 60 \times 20 \mathrm{~mm}$ not more than $10 \%$; ash content up to $2 \%$ of its dry weight. In addition, it is not allowed to add to biofuels substances that can negatively affect its storage, transportation and use in heating equipment. 


\section{The production of pellets and briquettes in terms of quality characteristics}

The rational use of waste of vegetable origin is a serious problem. Usually the direct use of waste for energy purposes is impossible due to their high moisture and inappropriate physical condition.

Difficulties arising from the use of biomass energy can be overcome by processing, which significantly increases their calorific value. These operations are expensive and energy consuming. However, the benefits of the new fuel (significant increase in density and calorific value, lack of $\mathrm{CO}_{2}$ emissions, reduction of $\mathrm{NO}_{\mathrm{x}}$ and $\mathrm{SO}_{2}$ emissions into the atmosphere which is EU legislation compliant) make it attractive for investment and promising.

\section{Combustion heat and calorific value}

Vegetable waste has a very high calorific value, being a good, environmentally friendly material for fuel.

As an example, the combustion heat and calorific value for sawdust, straw, paper, coal and bark (of oak, birch, alder, willow and pine bark) are given (Table 2).

Table 2

Combustion heat and calorific value of solid biofuels

\begin{tabular}{|l|c|c|}
\hline \multicolumn{1}{|c|}{ Tested material } & $\begin{array}{c}\text { Combustion heat, } \\
\text { MJ/kg }\end{array}$ & $\begin{array}{c}\text { Caloric value, } \\
\text { MJ/kg }\end{array}$ \\
\hline $\begin{array}{l}\text { Spruce sawdust } \\
\text { Straw: }\end{array}$ & 18,89 & 17,58 \\
Rye & 17,78 & 17,12 \\
Rapeseed & 19,14 & 17,82 \\
Buckwheat husk & 20,12 & 18,76 \\
Paper (waste & 17,05 & 16,39 \\
paper) & 31,55 & 30,23 \\
Charcoal & & \\
Bark: & 19,05 & 17,51 \\
oak & 23,37 & 21,86 \\
birch & 21,73 & 20,31 \\
alder & 18,19 & 16,76 \\
willow & 21,08 & 19,66 \\
pine & &
\end{tabular}




\section{Manufacturing of fuel briquettes and pellets}

Fuel briquettes and pellets that are formed in the process of agglomeration under pressure (granulation, briquetting), when the consolidation of bulk materials under the action of external pressure of compression and internal (intermolecular forces and bonds) forces, are formed of geometrically correct and uniform shape.

The use of compressed vegetable waste (briquettes and pellets) has many advantages.

Waste of vegetable origin, such as sawdust or chips, is usually heterogeneous and has particles of different sizes. For example, pine sawdust has the following particle size distribution: $31.3 \%$ of particles are retained on a sieve with a mesh of $1.5 \times 1.5 \mathrm{~mm}, 16 \%$ on a sieve of $1 \times 1$ $\mathrm{mm}, 13.5 \%$ on a sieve of $3 \times 3 \mathrm{~mm}$, and $15,4 \%$ on a $2 \times 2 \mathrm{~mm}$ sieve, and it is a good material for briquetting.

In industrial practice, the production of pellets can be conditionally divided depending on the type of equipment used (Fig. 1): a - in a closed chamber, a piston consolidation; b - in open chamber, a piston consolidation; c - in the open chamber, auger consolidation, and also depending on the type of matrix; $\mathrm{d}-\mathrm{a}$ flat matrix; $\mathrm{e}$ - an annular matrix.

The closed chamber pressing equipment (Fig. 1. a) is characterized by low energy consumption per unit of received products and enables the use of various materials and mixtures of vegetable origin as raw materials for pressing. The disadvantage is the complex mechanism of closing and opening the consolidation chamber and low efficiency.

Systems using open camera devices (Fig. 1. b) have a simpler design and higher efficiency. The disadvantages of such devices include high energy consumption and the need to use different types of matrices for pressing, depending on the material being pressed. The increase in energy consumption that results from friction forces in the process of briquette formation is partly a positive factor (when converting mechanical energy into thermal, there is an effect of bonding particles of material, which contributes to the formation of a better briquette).

Pressing of sawdust (straw cuttings) on the briquetting equipment (Fig. 1. c) is carried out by means of the auger 1 and the matrix 2, the obtained briquettes have a strong structure and hardened outer and inner cylindrical surfaces. 


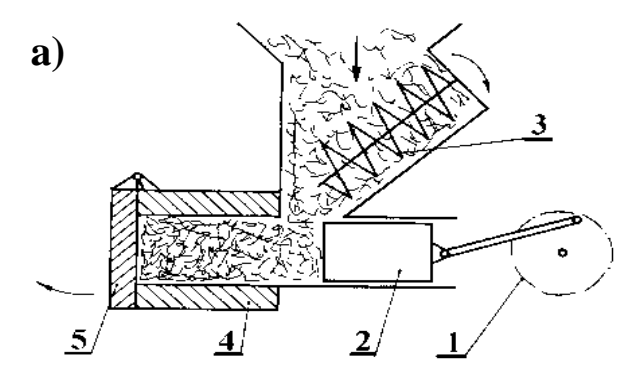

d)
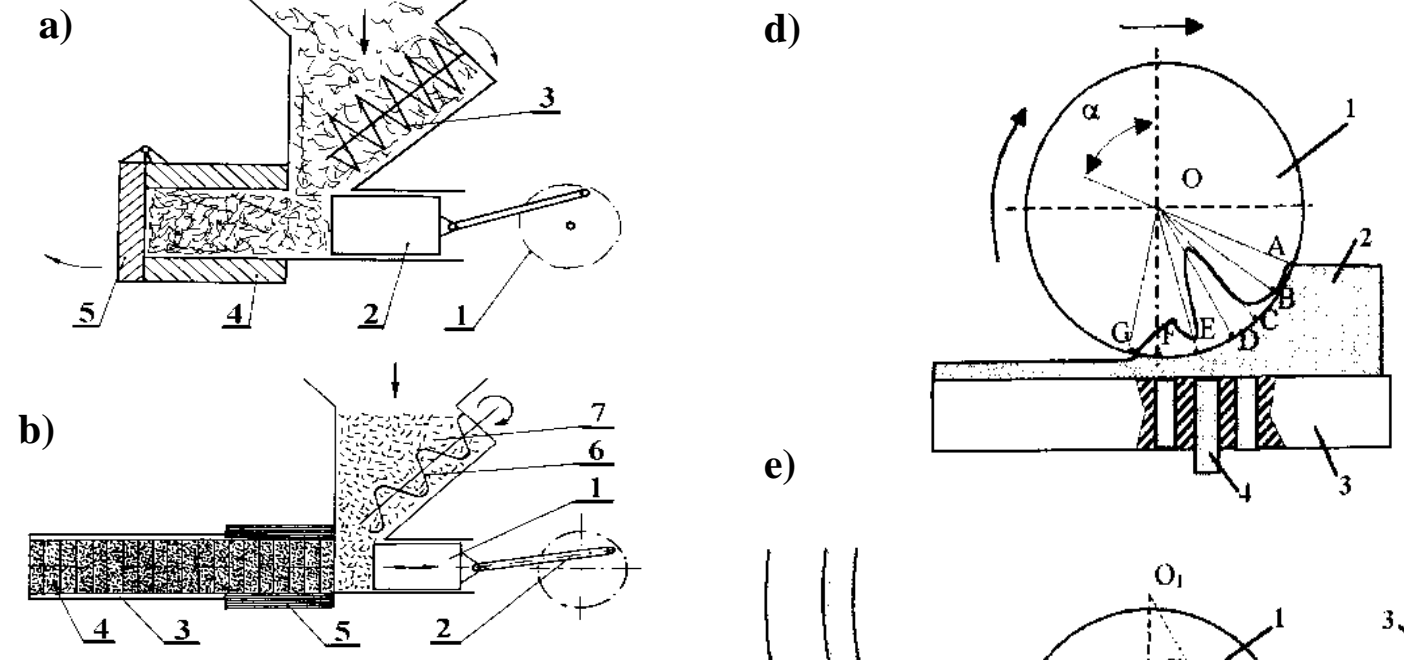

e)
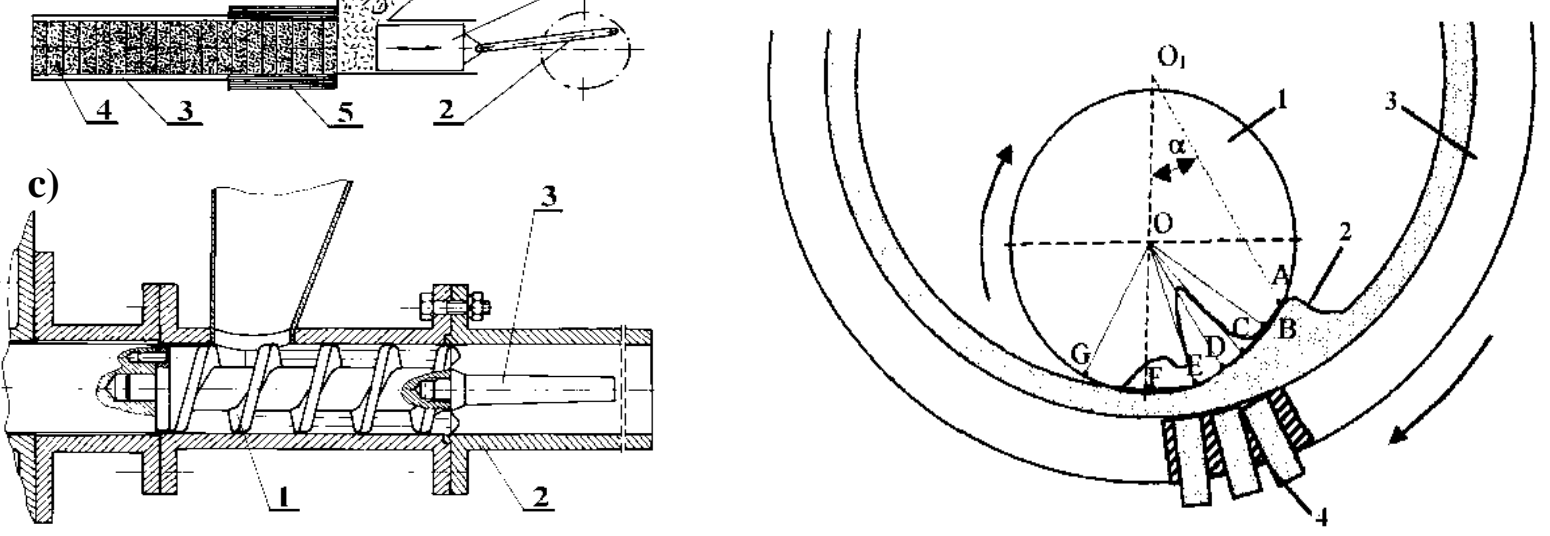

Fig. 1. Schemes of typical pressing equipment:

a) in a closed chamber, a piston consolidation: 1 - eccentric, 2 - piston, 3 - auger, 4 - consolidation chamber, 5 - movable plate; b) in open chamber, a piston consolidation: 1 - piston, 2 - connecting rod, 3 - consolidation chamber, 4 - briquettes, 5 - heater, 6 - auger, 7 -raw materials; c) in the open chamber, auger consolidation: 1 - pumping auger, 2 - matrix, 3 - shaft; d) on a flat matrix: 1 - consolidating roller, 2 - material, 3 - matrix, 4 - pellet; e) on the annular matrix: 1 - consolidating roller, 2 - material, 3 - matrix, 4 - pellet.

The granulation process is carried out in systems using a flat or annular pressing matrix (Fig. 1. $\mathrm{d}$ and 1. e). The process of pressing the crushed plant material in these systems is very similar. The material is first consolidated, getting into the wedge-shaped gap between the roller and the matrix, the final compression occurs in the holes of the matrix.

\section{The technological schemes for the production of solid bio-fuels}

In Fig. 2 and Fig. 3 there are technological schemes of biofuel production. 


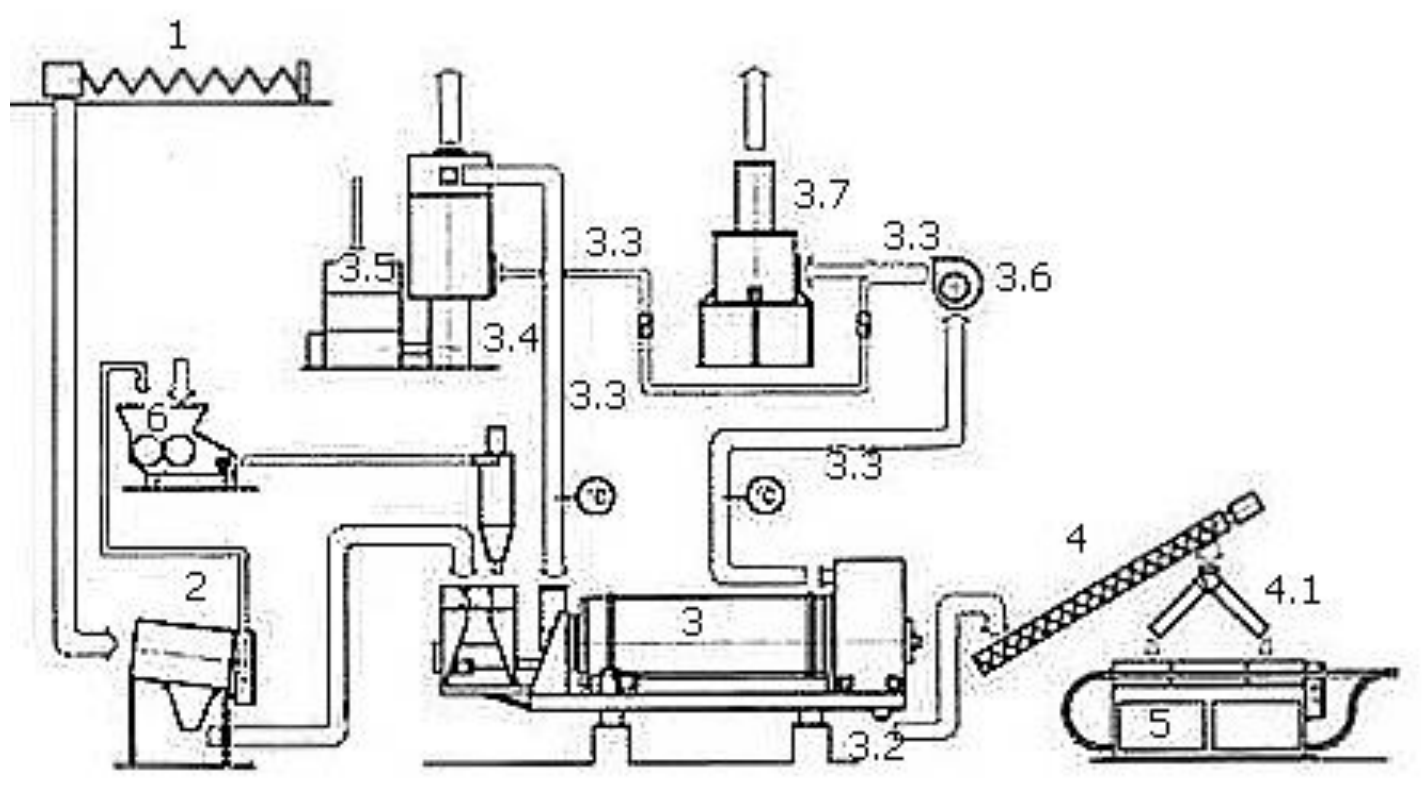

Fig. 2. Technological scheme of solid biofuel production

1 - Auger; 2 - Sieve; 3 - Drying chamber, 3.1 - Raw material bunker, 3.2 - A line for removing raw materials, 3.3 - Air pipelines, 3.4 - Boiler on raw material, 3.5 - Fuel bunker, 3.6 - Fan, 3.7 - Filter; 4. - Auger feed in the briquetter (granulator), 4.1 - Raw material distributor; 5. - Briquetting press (granulator); 6. - Waste crusher.

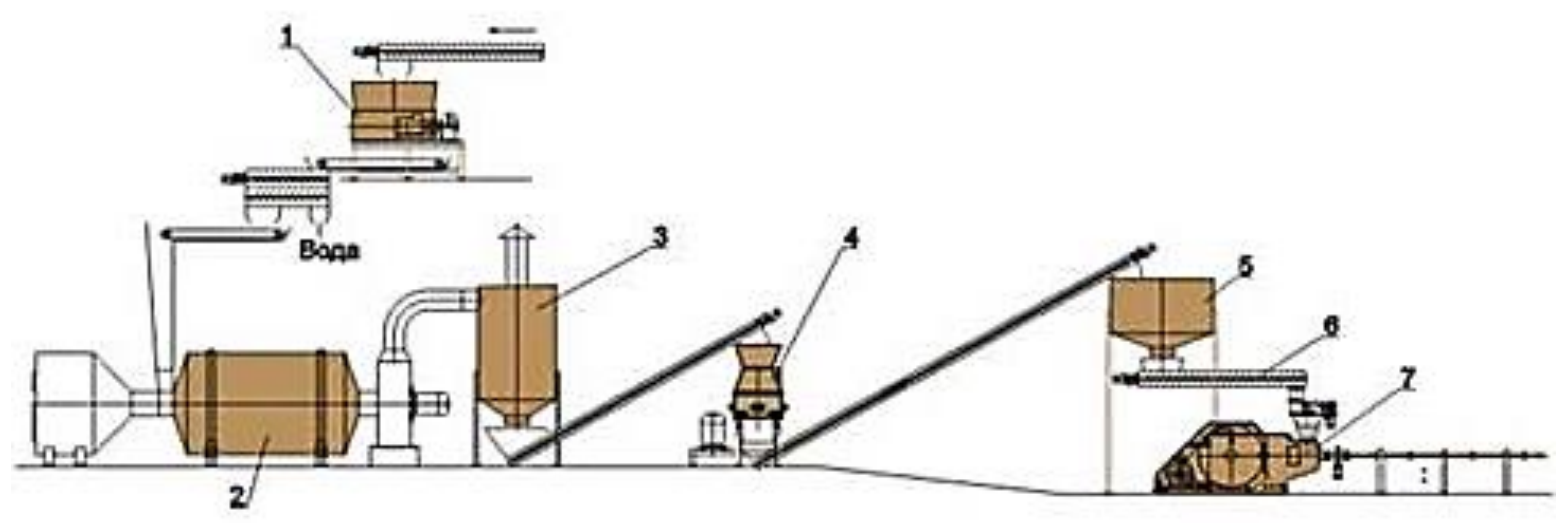

Fig. 3. Technological scheme of solid biofuel production

1 - a large fractional crusher; 2 - drying chamber; 3 - bunker; 4 -fine fractional crusher; 5-bunker; 6 -auger; 7 -briquetting press (granulator)

\section{The equipment for grinding of bio-raw materials}

The process of mechanical grinding is widely used in technological schemes for the production of solid biofuels. Thus, in a number of technologies, mechanical grinding of solid materials is applied, with their subsequent separation by size. The grinding result is characterized by the 
degree of grinding, which is determined by the ratio of the average characteristic size D of a piece of material before grinding to the average characteristic size $\mathrm{d}$ of a piece of material after grinding.

$$
i=\frac{D}{d} \text {. }
$$

The characteristic linear size of a piece of spherical shape is the diameter, a piece of cubic shape - the length of the rib. The characteristic linear size of pieces of irregular geometric shape can be found as the average geometric value:

$$
d_{x}=\sqrt[3]{l b h}
$$

where $l, b$, hare the maximum dimensions of a piece in three mutually perpendicular directions. The largest of these dimensions is $l$ - length, the medium is $b$-width, and the smallest is $h$-thickness.

To calculate the average characteristic size of the pieces, the material is divided into several fractions. In each fraction, the medium characteristic size is found as a half-sum of the characteristic dimensions of the maximum $\mathrm{d}_{\max }$ and the minimum $\mathrm{d}_{\min }$ pieces:

$$
d_{c e p}=\frac{d_{\max }+d_{\min }}{2} .
$$

The average characteristic size of a piece in the mixture is determined by the formula:

$$
d=\frac{d_{c p 1} a_{1}+d_{c p 2} a_{2}+\ldots+d_{c p n} a_{n}}{a_{1}+a_{2}+\ldots+a_{n}},
$$

where $\mathrm{d}_{\mathrm{cp} 1}, \mathrm{~d}_{\mathrm{cp} 2}, \ldots, \mathrm{d}_{\mathrm{cpn}}$ - the average sizes of the pieces of each fraction; $a_{1}, a_{2}, \ldots, a_{n}$ - the amount of each fraction, weight $\%$.

In the technology of production of solid biofuels from raw materials of plant origin, 2 stages of grinding are distinguished. The first stage is coarse grinding, before drying. The second stage is a fine grinding, just before pressing.

Coarse grinding. Crushers, for large grinding, grind raw materials for further drying. Grinding should reach a particle size of not more than $25 \times 25 \times 2 \mathrm{~mm}$. Coarse grinding allows quickly and qualitatively dry the raw material and prepares it for further grinding in a crusher, for fine grinding. 
Fine grinding. Raw materials should enter the press with a particle size of less than $4 \mathrm{~mm}$. Therefore, the crusher, for fine grinding, crushes the raw materials to the required size. In a crusher for fine grinding the raw material should usually come with a maximum particle size of $25 \times 25 \times 2 \mathrm{~mm}$.

Crushers of vertical and horizontal type are used for coarse grinding, depending on the method of raw material loading. Drum cutting machines and hammer crushers are most common.

For fine grinding hammer crushers and mills of different designs are used.

Drum cutting machines.

They are used for the production of technological and fuel wood chips, as well as "micro-chips" of round wood, balance, thin-hued humpback and other lumpy waste and substandard wood. Cutting units can have a capacity of 10 to 900 cubic meters of wood per hour (input).

Hammer crushers.

Hammer crushers have also become widely used in the production of briquettes and pellets (Fig. 4). Grinding of the material in them occurs under the influence of dynamic loads of mechanical hit. Effect on the body under concentrated load is similar to splitting, with distributed - crushing.

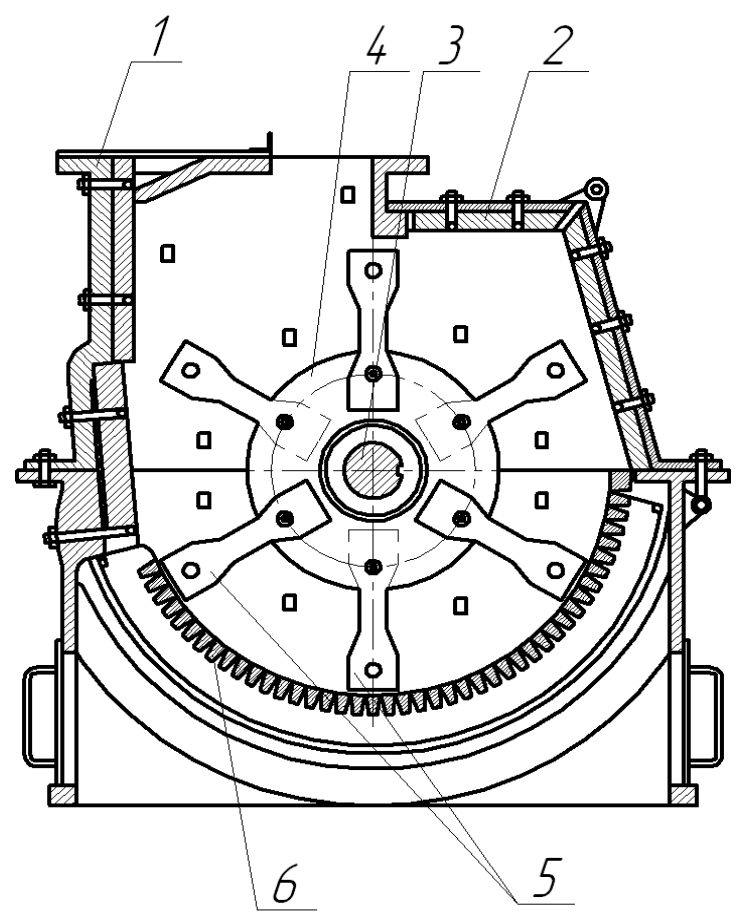

Fig. 4. scheme of a hammer crusher

1 - sieve; 2 - rod; 3 - hammer; 4 - branch pipe; 5 - feeder; 6 - shaft 
The main element of the crusher is the rotor, which has a horizontal shaft 6 with disks fixed at a certain distance by means of remote rings. To the disks on the rods 2 steel plate hammers 3 are mounted. As the shaft rotates, the material passes through the feeder 5 and the branch pipe 4 is processed by repeated hammer hits, crushed, passed through a sieve 1 and unloaded. The sieve condition is controlled through the hatch. Crushers with cam type hammers are used. As the rotor rotates, its velocity and kinetic impact energy must be sufficient to destroy the material. The critical (minimum) impact velocity, $\mathrm{m} / \mathrm{s}$, which ensures the grinding of the material depends on the initial particle size and is determined by the formula:

$$
v_{\kappa p}=175\left(\frac{\sigma_{P}}{\rho \cdot d_{\Pi}}\right)^{2 / 3},
$$

where $\sigma_{\mathrm{p}}$ is the ultimate tensile strength of the material, $\mathrm{MPa} ; \rho$ is the material density, $\mathrm{kg} / \mathrm{m}^{3} ; \mathrm{d}_{\Pi}-$ initial particle size of the material, $\mathrm{m}$

Impact velocity (rotor speed) when crushing pieces of wood is $60 \ldots 90 \mathrm{~m} / \mathrm{s}$. The performance of the hammer crushers, $\mathrm{kg} / \mathrm{h}$, it is recommended to calculate by the formula:

$$
G=\frac{K l D^{2} n^{2}}{3,6(i-1)},
$$

where $\mathrm{K}$ is the empirical coefficient (accept $\mathrm{K}=4,0 \ldots 6.2$ ); $l$-rotor length, $\mathrm{m} ; \mathrm{D}$ - rotor diameter, $\mathrm{m} ; \mathrm{n}-$ the rotor speed frequency, $\mathrm{min}^{-1}$; $\mathrm{i}$ - the degree of grinding.

The peculiarity of the hammer crusher is the considerable load that arises when grinding hard-to-process fibrous materials, such as wood, so when designing it should be taken into account as a heavy-duty housing and a reinforced sieve construction. The mass of the crusher absorbs all the vibration and the rigid body allows a very small gap between the hammers and the sieve.

One of the most important characteristics of hammer crushers is the so-called linear speed of rotation of the hammers. High speed hammers are best suited for fine grinding. Coarser grinding can be performed at lower speeds. 


\section{The equipment for drying bio-raw materials}

Drying is a must in the process of production of wood pellets.

By its physical nature, drying is a complex diffusion process, the speed of which is determined by the rate of diffusion of moisture from the surface of the material to be dried into the environment.

Material balance of air dryer.

If there is no loss of material, then the amount of completely dry matter in it before and after drying remains unchanged; if $m_{1}$ and $m_{2}-$ costs of wet material before and after drying, $\mathrm{kg} / \mathrm{s}$, and $\omega_{1}$ and $\omega_{2}-$ mass shares of moisture before and after drying, $\%$ to the total weight, the dry matter balance will be:

$$
\frac{m_{1}\left(100-w_{1}\right)}{100}=\frac{m_{2}\left(100-w_{2}\right)}{100},
$$

whence the weight of wet material:

$$
m_{1}=m_{2} \frac{100-\omega_{2}}{100-\omega_{1}}
$$

або маса висушеного матеріалу:

$$
m_{2}=m_{1} \frac{100-\omega_{1}}{100-\omega_{2}}
$$

The amount of moisture $W$, which is removed during drying, is equal to the difference in mass of wet and dried material:

$$
W=m_{1}-m_{2} .
$$

Substituting into the last equation the expression for $m_{2}$ we get:

$$
W=m_{1}-m_{1} \frac{100-\omega_{1}}{100-\omega_{2}} \quad \text { or } \quad W=m_{1} \frac{\omega_{1}-\omega_{2}}{100-\omega_{2}} .
$$

If we substitute instead of $m_{l}$ its expression from the equation, then

$$
W=m_{2} \frac{\omega_{1}-\omega_{2}}{100-\omega_{1}} \text {. }
$$

The material balance of the dryer by moisture will be made if we equate the amount of moisture brought into the dryer with wet material and with air, to the amount of moisture in the dried material and the used air:

$$
\frac{m_{1} \omega_{1}}{100}+L x_{1}=\frac{m_{2} \omega_{2}}{100}+L x_{2},
$$


whence

$$
\frac{m_{1} \omega_{1}}{100}-\frac{m_{2} \omega_{2}}{100}=\left(x_{2}-x_{1}\right) L,
$$

where $\mathrm{L}$ is the flow rate of absolutely dry air, $\mathrm{kg} / \mathrm{s}$.

The left side of the last equation is the amount of moisture that is removed during drying, that is:

$$
W=\left(x_{2}-x_{1}\right) L,
$$

where the total flow rate of completely dry air for drying is:

$$
L=\frac{W}{x_{2}-x_{1}} .
$$

The specific flow of air, that is, its consumption per $1 \mathrm{~kg}$ of moisture, which is removed from the material in the dryer:

$$
l=\frac{L}{W}=\frac{1}{x_{2}-x_{1}}=\frac{1000}{d_{2}-d_{1}},
$$

where $d_{2}, d_{1}-$ moisture after and before the dryer, $g / k g$.

As air passing through the heat exchanger does not absorb or give off moisture, its moisture content when heated in the heat exchanger remains unchanged, therefore, $x_{x}=x_{0}$ and therefore:

$$
l=\frac{1}{x_{2}-x_{0}}=\frac{1000}{d_{2}-d_{0}} .
$$

This equation is the basic equation for determining the air flow rate in a dryer. From this equation it can be seen that the air flow increases with increasing $x_{0}$. Due to the fact that the moisture of the outside air in the summer is higher than in the winter, the fan is calculated for the summer working conditions of the dryer.

The thermal balance of the air dryer

For a steady process, the heat balance equation expresses the uniformity of the amount of heat entering the drying device and the heat exiting it.

Heat input:

a) with fresh air, heat is introduced into the heat exchanger $L I_{0}$, where $I_{0}$ - enthalpy of air at its temperature $t_{0}$; 
b) from the heat source in the heater $\mathrm{Q}_{\mathrm{k}}$;

c) additional heat introduced into the drying chamber $\mathrm{Q}_{\text {д }}$;

d) with wet material $m_{1} c_{M} \theta_{1}$, where $m_{1}$ - the mass of material submitted for drying per unit time, $\mathrm{kg} / \mathrm{s} ; \mathrm{s}_{\mathrm{M}}$ - heat capacity of the material, $\mathrm{J} /(\mathrm{kg} \cdot \mathrm{K}) ; \theta_{1}-$ temperature of the material before drying, ${ }^{\circ} \mathrm{C}$.

Since by the equation $m_{x}=m_{2}+W$, we can write

$$
m_{1} \cdot c_{M} \cdot \theta_{1}=m_{2} c_{M} \theta_{1}+W c_{B} \theta_{1},
$$

where $\mathrm{c}_{\mathrm{B}}$ - heat capacity of water, $\mathrm{J} /(\mathrm{kg} \cdot \mathrm{K})$;

e) with transport devices $\mathrm{m}_{\mathrm{r},} \mathrm{c}_{\mathrm{T}, \mathrm{t}} \mathrm{t}_{\mathrm{r} . \mathrm{I}}$, де $\mathrm{m}_{\mathrm{T}}, \mathrm{c}_{\mathrm{T}}, \mathrm{t}_{\mathrm{r} . \mathrm{I}}$, - accordingly, the mass, heat capacity of the material of the transport device and its temperature at the inlet of the dryer.

Heat output:

a) with the outgoing air $L I_{2}$, where $I_{2}$ - enthalpy of air at its temperature $t_{2}$;

b) with the dried material $m_{2} c_{M} \theta_{2}$ where $\theta_{2}$ - temperature of the material at the outlet of the dryer;

c) with transport devices $\mathrm{m}_{\mathrm{T}} \mathrm{c}_{\mathrm{T}}, \mathrm{t}_{\mathrm{t}}$, where $\mathrm{m}_{\mathrm{T}}, \mathrm{c}_{\mathrm{T}}, \mathrm{t}_{\mathrm{T} . \mathrm{K}}$, - the temperature of the material of the transport device at the outlet of dryers;

d) loss of heat in the environment $Q_{\mathrm{H}}$.

The thermal balance of the dryer is expressed by the equation:

$$
\begin{aligned}
& L I_{0}+Q_{\kappa}+Q_{д}+m_{2} c_{M} \theta_{1}+W c_{B} \theta_{1}+m_{T} c_{T} t_{T I}= \\
& =L I_{2}+m_{2} c_{M} \theta_{2}+m_{T} c_{T} t_{T K}+Q_{H} .
\end{aligned}
$$

The total flow rate of heat in the dryer consists of $\mathrm{Q}_{K}$ and $\mathrm{Q}_{\mathbb{I}}$, so the last equation looks like:

$$
\begin{aligned}
& Q_{\kappa}+Q_{д}=L\left(I_{2}-I_{0}\right)+m_{2} c_{\mu}\left(\theta_{2}-\theta_{1}\right)+ \\
& +m_{T} c_{T}\left(t_{T K}-t_{T \Pi}\right)+Q_{H}-W c_{B} \theta_{1} .
\end{aligned}
$$

Let us divide each component of the heat balance by $\mathrm{W}_{\mathrm{i}}$ and obtain the specific heat consumption:

$$
\frac{Q_{\kappa}}{W}=q_{\kappa}, \frac{Q_{H}}{W}=q_{H}, \frac{L}{W}=l, \frac{W c_{B} \theta_{1}}{W}=c_{B} \theta_{1},
$$




$$
\frac{m_{2} c_{M}\left(\theta_{2}-\theta_{1}\right)}{W}=q_{M}, \frac{m_{T} c_{T}\left(t_{T K}-t_{T \Pi}\right)}{W}=q_{T} .
$$

Let us denote the total specific heat losses through the formula:

$$
\sum q_{B T P}=q_{M}+q_{E}+q_{B} .
$$

According to these designations the specific heat consumption for drying will be:

$$
q_{K}+q_{\text {д }}=l\left(I_{2}-I_{0}\right)+\sum q_{\text {BTP }}-c_{B} \theta_{1} .
$$

The specific consumption of heat in the heater at a given $\mathrm{q}_{д}$, we determine from the equation:

$$
q_{K}=l\left(I_{2}-I_{0}\right)+\sum q_{\text {ВТР }}-c_{B} \theta_{1}-q_{\text {д }} \cdot
$$

The specific heat consumption in the heat exchanger can also be determined from the equation:

$$
q_{K}=l\left(I_{2}-I_{1}\right) .
$$

Equating the right parts of these equations, we get:

$$
l\left(I_{2}-I_{1}\right)=\left(q_{\text {д }}+c_{B} \theta_{1}\right)-\sum q_{B T P} .
$$

Let us denote the right side of this equation by $\Delta$ :

$$
\Delta=\left(q_{\text {д }}+c_{B} \theta_{1}\right)-\sum q_{\text {BTP }} .
$$

Then

$$
l\left(I_{2}-I_{1}\right)=\Delta .
$$

For the analysis and calculation of drying processes, it is advisable to introduce the concept of the so-called theoretical dryer, which operates without additional supply of heat in the drying chamber $\left(\mathrm{q}_{\text {д }}=0\right)$, without heat losses $\left(\sum \mathrm{q}_{\mathrm{втр}}=0\right)$ and at $\theta_{1}=0$. According to the equation for such a dryer $\Delta=0$, then we get the equations $l\left(I_{2}-I_{1}\right)=0$ or $I_{2}=I_{1}=I=$ const

The process in a theoretical dryer occurs at constant enthalpy of air. In this case, the heat released during the cooling of the air is spent only on the evaporation of moisture from the material, and therefore, together with the steam formed, is again returned to the air. 
Based on the above considerations, the value of $\Delta$ is called the thermal characteristic of the dryer ${ }^{1,2}$.

\subsection{Drum dryers}

For a number of reasons, in the biofuel industry, as well as in many other industries where the drying of large volumes of bulk materials is most widespread, the drying units of the drum type have become popular. These dryers are widely used for continuous drying at atmospheric pressure of lumpy, granular and bulk materials (Fig. 5).

The unit capacity of such a dryer can be up to 20 tons per hour or more. The advantages of drying technology in the drum are reasonable cost, proven, reliable, traditional technology, careful drying, that ensures the preservation of all material properties, high energy efficiency.

The scheme of the drum type drying unit with solid fuel heat generator is presented in Fig. 6.

Sometimes a biomass furnace may be included in the drying complex, which produces the hot gases required for drying.

When installing a drum dryer in the open air, it is necessary to additionally carry out thermal insulation of the main cyclone, the gate lock to avoid condensation of moisture at these nodes. The thermal insulation of the drum is necessary in any case.

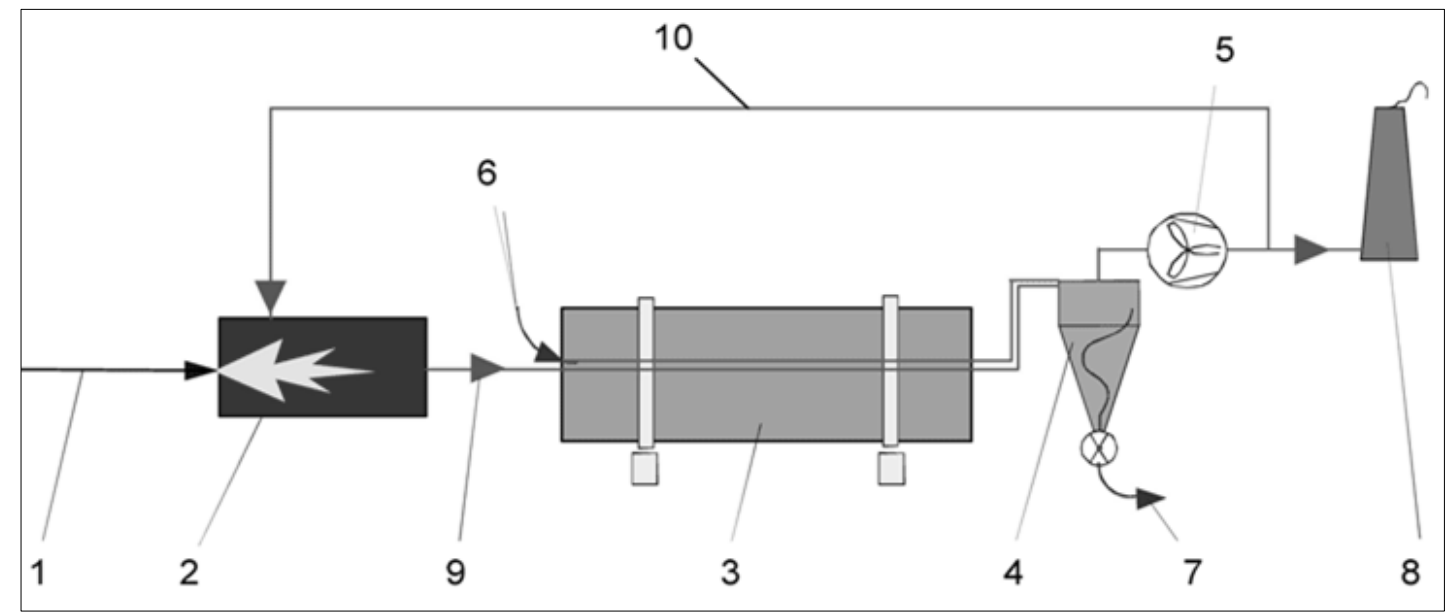

Fig. 5. Scheme of drying in the dryer of the drum type:

1 - fuel; 2 - heat-generating unit; 3 -drum; 4 - cyclone; 5 - fan; 6 - supply of wet material; 7 - gate valve; 8 - coolant eject pipe; 9 - coolant; 10 - reusable coolant.

\footnotetext{
${ }^{1}$ Bogdanovich V.P., Shevchenko N.V. Perspectives of alternative fuel use in agriculture. Machinery in agriculture. 2012. № 5. P. 38-40.

${ }^{2}$ Sukhenko Yu.G., Seryogin O.O., Sukhenko V.Yu., Ryabokon N.V. Resource-saving technologies in food and processing industries. Textbook. K. 2016.
} 
Wet material is given into the drum 6. The coolant 9 (combustible gases in admixture with air) is heated in the heat generating unit 2 and comes into contact with the material inside the drum 3 . The constant rotation of the drum and the partitions (blades) installed inside it ensure a constant finding of the material in the coolant flow, which leads to intensive evaporation of moisture. In addition, this interaction effectively separates the small and light particles of the material that dry quickly from larger, heavier, wetter particles. The small dry fraction quickly leaves the drum, caught by the coolant flow. The large fraction remains inside the drum for a longer time until leaves it with the proper moisture level. The coolant is transported from the heat generating unit via a drum to the main cyclone 4 of the drying unit by means of a powerful main fan 5 . In the cyclone, the dried product is separated from the coolant stream. The used coolant (air saturated with water vapor) is released into the atmosphere through the coolant eject pipe 8. A large gate valve 7 is installed under the cyclone, which retains the coolant and releases the dried product for further processing.

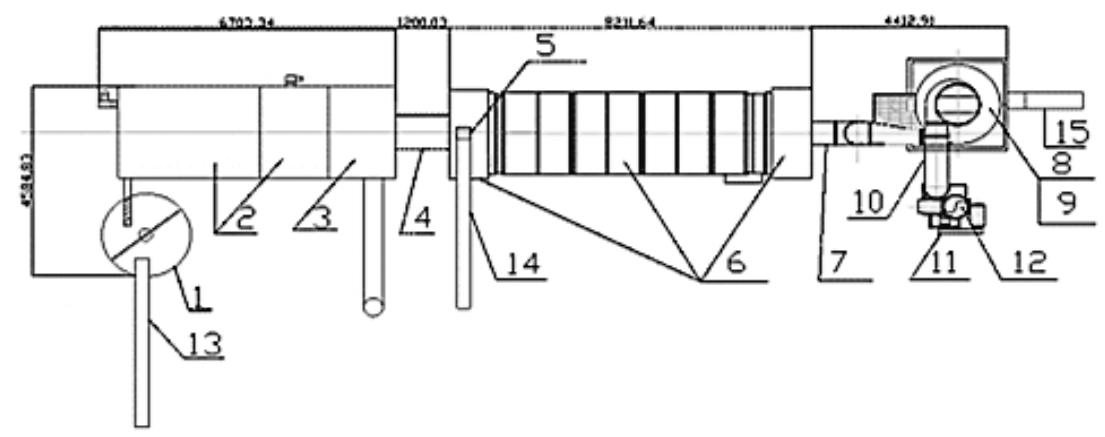

Fig. 6. Drying complex of drum type with solid fuel heat generator:

1 - fuel bunker; 2 - mixing chamber; 3 - sparking redemption system; 4 - gas pipeline; 5 - raw material loading feeder; 6 - loading bunker; drying drum; unloading bunker; 7 - coolant outlet pipeline; 8 - cyclone of purification of the coolant from a small fraction of dry raw material; 9 - cyclone feeder; 10 - gas pipeline to the smoke exhaust; 11 - the smoke exhaust; 12 - the smoke exhaust pipe; 12 - conveyor loading fuel into the fuel bunker; 14 - conveyor loading of raw material into the dryer feeder; 15 - conveyor of raw material feed for the following technological operations.

Items 1-3 can be replaced by a gas burner with a mixing chamber. Coolant: flue gases in admixture with air.

The temperature maintained at the inlet of the drum depends on the characteristics of the drying unit and its mode of operation - the required performance, the initial moisture of the product, etc. Most often it is 
maintained at $250 \ldots 450{ }^{\circ} \mathrm{C}$. As the material moves through the drum, its moisture decreases, but at the exit of the drum the temperature of the coolant and the material itself is much lower than the combustion temperature. The temperature of the coolant at the outlet of the drum should be above the dew point to avoid condensation of the steam. It is usually maintained at $70 \ldots 110{ }^{\circ} \mathrm{C}$.

\subsection{Belt dryers}

Belt drying complexes (Fig. 7) are used in conjunction with drum dryers for biomass drying.

Belt drying complexes for wood chips and sawdust have several advantages over drum dryers. Low-temperature belt-type drying unit, which uses hot water as a coolant, saves electricity, has a low level of harmful emissions (no additional measures are needed to clean up emissions), enables the use of low-temperature energy, provides gentle drying, which preserves all material properties, automates the production process.

The disadvantages of belt dryers include: high cost, very stringent requirements for uniformity of material in fractional composition and initial moisture, difficult to maintain (due to warps and stretching of the belts), has a large number of moving parts, specific productivity is low, and the specific flow rate is quite high.

It is ideal to use belt dryers in the presence of excess heat capacity of an existing boiler or process heat. The hot water is a coolant with a temperature of $90 \ldots 110^{\circ} \mathrm{C}$.

Sometimes the belt dryer is equipped with a biomass boiler, through which the water will be heated to $105^{\circ} \mathrm{C}$ in the amount required for drying.

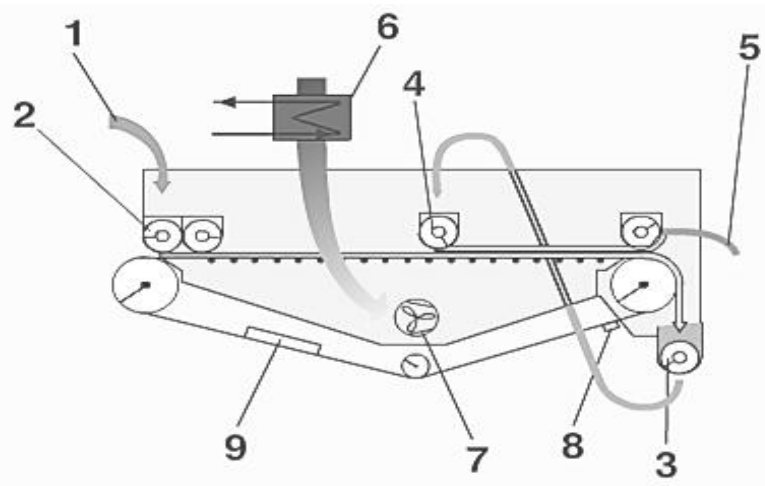

Fig. 7. The scheme of drying in a belt dryer:

1 - wet material; 2 - auger feeder I; 3 - unloading auger I; 4 - auger feeder II; 5 unloading of dry material; 6 - heat exchanger; 7 - exhaust fan; 8 - cleaning brush; 9 a device for washing the belt. 
With the help of the conveyor wet material 1 is dosed fed into the auger feeder 2, which evenly distributes it throughout the width of the belt. The amount of fed material is regulated by changing the torque of the auger feeder 2, which allows a uniform filling of the auger. The product layer is transported through the drying chamber together with the belt to the unloading auger I. With the help of an additional auger feeder, the unloaded product is returned to the auger feeder II, which re-distributes the material on the belt over the first layer. After re-passing of the part of the length of the drying chamber, the material is unloaded for further processing. The use of such a dual system allows to achieve the maximum saturation of the drying agent (gas) with moisture and thus - the maximum energy efficiency of the process. At the outlet of the dryer 5 the moisture of the material is controlled. According to the results of this control, a signal is sent that regulates the speed of the belt and thus the bandwidth (performance) of the drying unit. Thus, the performance of the dryer depends on the amount of heat available. The exhaust fan 7 draws the outside air through the heat exchanger 6 , where the air is heated before it enters the drying chamber and passes through the material layer and the perforated belt itself. As it passes through the drying chamber, the material on the belt dries. Moisture-rich air leaves the drying chamber through the coolant discharge pipe. The fan output is controlled by a frequency transducer, depending on the thermal power supplied to the heat exchanger. For optimum performance, the unit is equipped with a brush 8 and a washing system 9 that clean the belt during the dryer operation.

\section{The presses for bio-fuel granulation}

Methods of granulation by molding and extrusion are based on the ability of dispersed materials to form pellets of the desired shape and size as a result of the force action of the working bodies on the treated mass and pushing it through the holes.

Granulation by molding involves a number of steps:

- preparation of the initial product;

- molding or extrusion (forcing the mass through the perforated surface by force action);

- cooling, crushing, size classification of pellets.

Granulation presses are classified: 
- on the principle of pressing - in presses with closed and open chambers, in which the pressure is created respectively by a blank wall and the force of friction against the side wall of the camera;

- on the type of workpieces that create the compression force, the following: auger, plunger, roller and combined.

\subsection{Auger granulators}

Screw granulators can be cylindrical and conical, single- and twinauger, with horizontal and vertical arrangement of augers.

Fig. 8. depicts one of the possible designs of a auger granulator.

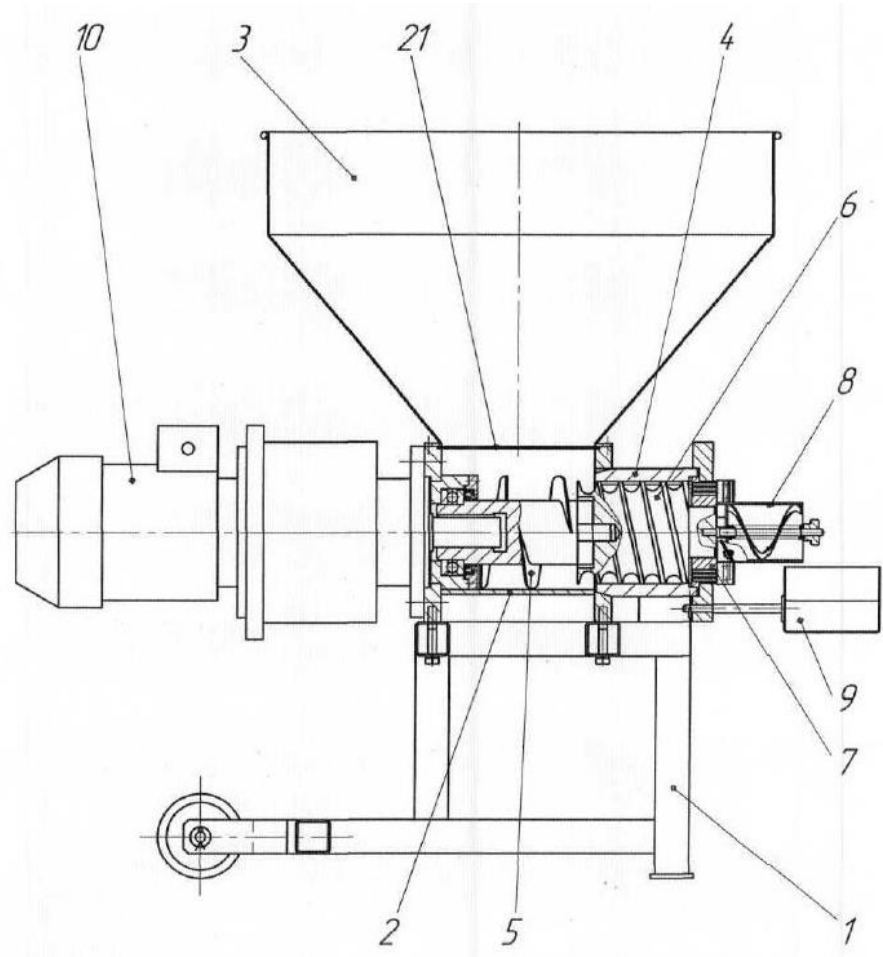

Fig. 8. Schematic diagram of the auger granulator:

1 - frame; 2 - receiving chamber; 3 - receiving bunker; 4 - working chamber; 5 - feeding auger; 6 - pressing auger; 7 - annular matrix; 8 - pelletizing device; 9 - tray; 10 - drive; 11 - hatch

The granulator consists of a frame 1 on which a receiving chamber with a receiving bunker 3 and a working chamber 4 are mounted, in which the feeding 5 and pressing augers 6 are located.

At the end of the working chamber the annular matrix 7 with die for extruded product is fixed. On the outside of the matrix 7 pelletizing device 
8 and tray 9 for waste disposal are placed. The drive of the augers 5 and 6 , as well as the pelletizing device 8 is carried out from the general power drive 10.

The granulator works in this way: the raw material is loaded into the receiving bunker 3 and when the power drive 10 is on, it is supplied by the feeding auger 5 to the pressing auger 6 , which pushes the product through the die of the matrix 7. At the exit of the die of the matrix 7, the product bundles are cut into pellets with the blades of the main knives. The length of the pellets depends on the number of blades and the amount per unit time of product coming in and can be adjusted by the hatch 11 of the receiving chamber 2 .

\subsection{Plunger extruders}

In plunger extruders widely used in the production of fluoroplasts, unlike auger ones, molding is the result of uniaxial compression. Typically, a large portion of material is loaded into the cylinder of the plunger extruder, which is substantially unmixed in the molding process. This complicates the warming of the molded material.

\subsection{Roller granulators}

Roller granulators are divided into:

1. According to the location of the axes of the pressing rolls:

- granulators with vertical arrangement of axes of the pressing rolls;

- granulators with horizontal arrangement of axes of pressing rolls.

2. By type of drive mechanism:

- the matrix is stationary, only the pressing rollers are driven;

- the matrix and the pressing rollers are driven;

- only the matrix is driven.

Granulators with vertical arrangement of axes of the pressing rolls.

The rolls can be conical and cylindrical with active and passive drive. In cylindrical roller presses, matrices and rolls wear out irregularly due to the difference in wheel speeds. Among disadvantages there is also certain circumferential velocity of the material attribution under the action of centrifugal forces to the periphery of the matrix and, as a consequence, an uneven load on its working surface.

When granulating on a flat matrix, the rollers are often driven, and the matrix is fixed permanently. The material comes from above, falling on the 
matrix, and then the roller rolls upon it, and it is forced through the holes in the matrix.

Granulators with horizontal arrangement of axes of pressing rolls.

In cylindrical matrix granulators, the rollers are most often fixed permanently and the matrix is driven and rotates around them vertically. The granular material is backfilled on the side of the end face of the matrix, entrained by it in rotational motion and, being in the wedge space between the matrix and the roller, which also rotates under the action of friction forces, is forced through the radial holes of the matrix. This method of granulation is more rational than the previous one in terms of machine design, process energy consumption and wear resistance of the matrix and rollers.

\section{The calculation of the design of the press granulator}

The design of the press-granulator is related to the calculation of the geometric dimensions of the matrix and the pressing roller. In practice, a press pair having from one to three rollers is used, and the rollers, like the matrix, can have a drive. Often rollers are placed inside the annular matrix, but there is an external installation of the pressing roller.

Let us consider the most typical case where the roller is located inside the annular matrix, where the radius of the matrix $\mathrm{R}$ is greater than the radius of the roller ${ }^{3,4,5,6,7,8}$.

\section{REFERENCES}

1. Bogdanovich V.P., Shevchenko N.V. Perspectives of alternative fuel use in agriculture. Machinery in agriculture. 2012. № 5. P. 38-40.

2. Arndt E. Renewable energy sources in Germany: problems and prospects. Innovations + Publicity. 2010. № 2. P. 30-31.

\footnotetext{
${ }^{3}$ Arndt E. Renewable energy sources in Germany: problems and prospects. Innovations + Publicity. 2010. № 2. P. 30-31.

${ }^{4}$ Baer G.Ya., Yemets A.I., Stadnichuk N.A., Ya.B. Blume, Rakhmetov D.B. Somaclonal Variability As a Source for Creation of New Varieties of Finger Millet (Eleusine coracana (L.) Gaertn.) .Cytology and genetics Vol. 41, No 4. Allerton Press. 2007. P. 204-208.

${ }_{5}$ Belyakov A.I., Korchevskiy A.A., Spinko V.E. Alternative Perspectives. Academy of Energy. 2010. № 1 (33): February. P. 50-54.

${ }^{6}$ Zhelykh V.M. Non-traditional energy sources. O.T. Wozniak, Yu.S. Yurkevich, Lviv: Publishing House of Lviv Polytechnic National University. 2009. 83 p.

Sukhenko Yu.G., Seryogin O.O., Mushtruk M.M., Ryabokon N.V. Innovative technologies of alternative energy supply of food and processing enterprises in examples and problems. Training manual. PC "Comprint", K. 2016.

${ }^{8}$ Sukhenko Yu.G., Seryogin O.O., Sukhenko V.Yu., Ryabokon N.V. Resource-saving technologies in food and processing industries. Textbook. K. 2016.
} 
3. Baer G.Ya., Yemets A.I., Stadnichuk N.A., Ya.B. Blume, Rakhmetov D.B. Somaclonal Variability As a Source for Creation of New Varieties of Finger Millet (Eleusine coracana (L.) Gaertn.). Cytology and genetics Vol. 41, No 4. Allerton Press. 2007. P. 204-208.

4. Belyakov A.I., Korchevskiy A.A., Spinko V.E. Alternative Perspectives. Academy of Energy. 2010. № 1 (33): February. P. 50-54.

5.Zhelykh V.M. Non-traditional energy sources. O.T. Wozniak, Yu.S. Yurkevich, Lviv: Publishing House of Lviv Polytechnic National University. 2009. $83 \mathrm{p}$.

6. Yu.G. Sukhenko, O.O. Seryogin, M.M. Mushtruk, N.V. Ryabokon. Innovative technologies of alternative energy supply of food and processing enterprises in examples and problems. Training manual. PC "Comprint", K. 2016.

7. Yu.G. Sukhenko, O.O. Seryogin, V.Yu. Sukhenko, N.V. Ryabokon. Resource-saving technologies in food and processing industries. Textbook. K. 2016.

\section{Information about the author:} Domnich V. I.

Candidate of Technical Sciences, Professor, Head at the Department of Automated Process Control of the V. I. Vernadsky Taurida National University 